\title{
O impacto da aposentadoria nas pessoas com doença de Parkinson em idade ativa
}

\author{
Angela Maria Alvarez ${ }^{1}$, Rafaela Vivian Valcarenghi ${ }^{2}$, Simony Fabíola Lopes Nunes ${ }^{3}$, \\ Josiane Steil Siewert ${ }^{4}$, Rafaela Baptista ${ }^{5}$
}

\footnotetext{
${ }^{1}$ Enfermeira, Doutora em Enfermagem. Professora Associada da Universidade Federal de Santa Catarina. Florianópolis, SC, Brasil. E-mail: angela.alvarez@ufsc.br.

${ }^{2}$ Enfermeira, Doutora em Enfermagem. Professora Substituta do Instituto Federal de Santa Catarina. Florianópolis, SC, Brasil. E-mail: rafaelavalcarenghi@yahoo.com.br.

${ }^{3}$ Enfermeira, Mestre em Enfermagem. Professor Assistente da Universidade Federal do Maranhão. Imperatriz, MA, Brasil.E-mail: sflnunes@hotmail.com.

${ }^{4}$ Enfermeira, Mestre em Enfermagem. Professor Substituto do Instituto Federal de Santa Catarina. Joinville, SC, Brasil. Email: josianes@ifsc.edu.br.

${ }^{5}$ Enfermeira, Mestre em Enfermagem. Enfermeira do Hospital Universitário Polydoro Ernani de São Thiago da Universidade Federal de Santa Catarina. Florianópolis, SC, Brasil. E-mail: rafaela_tenbap@yahoo.com.br.
}

Recebido: 16/03/2016.

Aceito: 21/02/2017.

Publicado: 12/06/2017.

\section{Como citar esse artigo}

Alvarez AM, Valcarenghi RV, Nunes SFL, Siewert JS, Baptista R. O impacto da aposentadoria nas pessoas com doença de Parkinson em idade ativa. Rev. Eletr. Enf. [Internet]. 2017 [acesso em: ____19:a16. Disponível em: http://dx.doi.org/10.5216/ree.v19.39607.

\section{RESUMO}

Estudo com objetivo de compreender o impacto da aposentadoria nas pessoas com doença de Parkinson em idade ativa. Trata-se de pesquisa qualitativa, que utilizou como Referencial Metodológico a Teoria Fundamentada nos Dados. Foram entrevistados 30 indivíduos com doença de Parkinson, dos quais seis se aposentaram em idade ativa. Os dados foram coletados de setembro de 2013 a abril de 2014 e analisados por meio das técnicas de codificação aberta, axial e seletiva. Da análise emergiram quatro categorias: aposentadoria e a identidade na doença de Parkinson; a incompatibilidade entre o desejo e a capacidade para o trabalho; desligando-se e encarando a realidade; o inesperado da aposentadoria. Os resultados indicaram que a pessoa enfrenta dificuldades no processo de aposentadoria por invalidez, sendo identificadas necessidades de acompanhamento emocional e preparação para esse momento de transição de forma a estimular um viver produtivo, mesmo com a doença de Parkinson.

Descritores: Doença de Parkinson; Aposentadoria; Doença Crônica; Enfermagem Geriátrica.

\section{INTRODUÇÃO}

A doença de Parkinson (DP) é considerada uma afecção degenerativa do sistema nervoso central que acomete principalmente o sistema motor, caracterizada por sinais motores clássicos do parkinsonismo associado com corpos de Lewy e perda de neurônios dopaminérgicos na substância negra ${ }^{(1)}$. Quanto à epidemiologia, a DP representa $80 \%$ dos casos de parkinsonismo, incidindo majoritariamente em pessoas com mais de 50 anos e prevalência em cerca de 550 por 100.000 pessoas aos 70 anos de idade ${ }^{(2)}$, muitas ainda em idade produtiva e com responsabilidades profissionais e familiares. 
As pessoas com DP podem apresentar comprometimento na qualidade de vida por vivenciar condições relacionadas às limitações físicas, com significativas modificações no cotidiano, comprometimento da capacidade funcional, profissional e social ${ }^{(3)}$. Essas alterações podem interferir diretamente na atividade laboral, afetando a capacidade de realizar os afazeres, podendo ainda causar depressão, isolamento e desinserção do mercado de trabalho.

As consequências socioeconômicas para pessoas com DP incluem menores taxas de emprego e renda, com impacto na vida social. Na Suécia, entre as pessoas com 10 anos ou mais de evolução da doença, $24 \%$ permanecem empregadas e $6 \%$ trabalham em tempo integral ${ }^{(4)}$. Na Irlanda, cerca de $88 \%$ das pessoas com Parkinson permanecem trabalhando após o primeiro ano do diagnóstico, $40 \%$ após cinco anos e $14 \%$ após 10 anos $^{(5)}$. No Brasil não há dados estatísticos sobre a taxa de empregabilidade de pessoas com DP.

Em estudo sobre a temática do contexto das Políticas Públicas de Saúde no Brasil para pacientes com DP, a aposentadoria pela previdência social é destacada como benefício aos doentes de Parkinson que pode contribuir para melhorar sua condição e qualidade de vida ${ }^{(6)}$.

A aposentadoria por invalidez é o benefício concedido ao segurado que, "estando ou não em gozo de auxílio-doença, é considerado incapaz para o trabalho e insuscetível de reabilitação para o exercício de atividade que the garanta a subsistência". Segundo dados da Previdência Social, entre 2013 e 2015 foram concedidas 468.378 aposentadorias por invalidez no meio urbano. Desse total, foram $100.902(21,54 \%)$ na Região Sul, dos quais 31.903 em Santa Catarina ${ }^{(7)}$. Nesse contexto, a relação da DP com o trabalho envolve múltiplas questões relacionadas à perda de papéis sociais e de poder. Provavelmente o afastamento do trabalho motivado pela aposentadoria, tanto programada como precoce - por invalidez - seja a perda mais importante na vida social desses indivíduos ${ }^{(8)}$.

Diante do exposto, o estudo tem como objetivo compreender o impacto da aposentadoria nas pessoas com doença de Parkinson em idade ativa.

\section{MÉTODOS}

Trata-se de pesquisa qualitativa, que teve como Referencial Metodológico a Teoria Fundamentada nos Dados (TFD). Essa teoria está voltada para o conhecimento da percepção, do significado ou da maneira como as pessoas definem os eventos ou a realidade e como agem em relação às suas crenças ${ }^{(9)}$.

O estudo faz parte de um macroprojeto intitulado "Vivendo com a doença de Parkinson", do qual participaram 30 pessoas diagnosticadas com a doença e que tinham cadastro na Associação Parkinson Santa Catarina (APASC). Foram critérios para integrar a pesquisa: diagnóstico da DP; condição cognitiva preservada, conforme escore do Mini Exame do Estado Mental (MEEM); e condições de se comunicar verbalmente com a pesquisadora.

As pessoas cadastradas na APASC foram convidadas a participar da pesquisa por telefone ou pessoalmente. Os dados coletados entre pessoas recém-diagnosticadas evidenciaram que o viver com a DP pode ser permeado por diversas simbologias no decorrer do processo de conviver com doença crônica. 
Assim, para buscar dados que corroborassem e/ou redirecionassem tal achado, foram compostos os grupos amostrais: Grupo amostral 1 - Pessoas com tempo de diagnóstico da DP até cinco anos (incompletos): 14 participantes; Grupo amostral 2 - Pessoas com tempo de diagnóstico da DP de cinco anos a 10 anos (incompletos): sete participantes; Grupo amostral 3 - Pessoas com tempo de diagnóstico da DP acima de 10 anos: nove participantes.

Dos participantes, seis relataram a aposentadoria ainda em idade ativa, devido às condições impostas pela doença. Os seis entrevistados fazem parte deste corpus de análise, dos quais três mulheres e três homens, com idades no período da coleta de dados entre 44 anos e 60 anos, e tempo de diagnóstico da doença de Parkinson variando de dois a 10 anos.

Os dados foram coletados no período de setembro de 2013 a abril de 2014 por meio de entrevistas em profundidade, com as questões formuladas de forma ampla e geral, a fim de contemplar uma variedade de experiências e também restritas, para extrair e revelar a experiência específica de cada participante ${ }^{(9)}$. Para tal, foram utilizadas questões norteadoras, como: - Fale-me sobre sua vivência com a doença de Parkinson. - Após o diagnóstico da doença, teve alguma modificação nas suas atividades diárias?

Outros questionamentos emergiram do diálogo estabelecido com base nas perguntas iniciais e para aprofundar os achados das entrevistas anteriores.

As entrevistas foram gravadas e transcritas na íntegra, cujo texto foi analisado de acordo com as técnicas de codificação da TFD, que se processa em três etapas: codificação aberta, codificação axial e codificação seletiva. Nessa metodologia, a coleta e análise dos dados acontecem em sequência alternada: a análise começa com a primeira entrevista que conduzirá à próxima. Ou seja, a análise conduz a coleta dos $\operatorname{dados}^{(9)}$

A pesquisa foi submetida ao Comitê de Ética em Pesquisas com Seres Humanos da Universidade Federal de Santa Catarina, que o aprovou no Parecer no 329.662. Os participantes leram, entenderam e assinaram o Termo de Consentimento Livre Esclarecido (TCLE). Para não identificá-los, os participantes do estudo foram nominados com a letra "P" de participante, seguida de algarismo arábico da ordem cronológica de realização das entrevistas: P1, P2, P3 e assim por diante.

\section{RESULTADOS}

O procedimento de análise da TFD permitiu desvelar o fenômeno central "Vivendo com a doença de Parkinson", do qual se originaram quatro categorias relativas ao impacto da aposentadoria em pessoas em idade ativa: aposentadoria e a identidade na doença de Parkinson; a incompatibilidade entre o desejo e a capacidade para o trabalho; desligando-se do trabalho e encarando a realidade; e o inesperado da aposentadoria.

\section{Aposentadoria e a identidade na doença de Parkinson}

Os participantes deste estudo foram instados a parar de trabalhar devido às limitações impostas pela 
DP, o que lhes causou sentimentos diversos, como frustração e tristeza, como fica evidente nos depoimentos a seguir.

[...] eu continuei a trabalhar, mas o Parkinson, em alguns casos, leva à depressão; aí eu entrei numa fase de depressão, comecei a ter crise de choro no trabalho (P1)

[...] na idade, mais ou menos meia idade, jovem ainda, com 40 anos, você não está preparado para se aposentar com uma doença neurodegenerativa, então isso para mim foi ruim [...] (P2)

\section{A incompatibilidade entre o desejo e a capacidade para o trabalho}

Nos depoimentos dos participantes deste estudo, destacam-se as alterações físicas impostas pela doença e sua relação com o trabalho.

[...] não consigo trabalhar, não consigo fazer nada, porque trabalha um dia, fica uma semana doente, tenho muita dor muscular (P3)

Eu me aposentei pelo Parkinson, o médico falou: "Eu vou dar o encaminhamento para o senhor porque o senhor tem direito, todo mundo tem". Aí me deram o benefício. Eu sentia muita dificuldade para fazer as coisas. A pessoa que tem essa doença é diferente (P6)

\section{Desligando-se do trabalho e encarando a realidade}

É importante ressaltar que, em sua grande maioria, as pessoas aposentadas por invalidez não passam por orientação profissional para encerrar sua relação com o trabalho, não existe planejamento nem preparação para esse processo, como se percebe nos relatos a seguir.

[...] eu não rendia mais, começou a reverter em dificuldades no trabalho, aí eu entrei em licença médica, e atualmente estou aposentado por invalidez ( $P 1)$

[...] Eu atualmente estou aposentada, fui aposentada por invalidez [...] me propuseram um período de licença médica que eu aceitei. Só que depois essa licença se transformou em aposentadoria sem eu ter sido consultada, então o meu projeto profissional foi todo por água abaixo; eu fiquei bastante abatida com isso no semestre passado, eu acho que fiquei bem deprimida [...] (P5)

Destaca-se, ainda, nos relatos, a relação do indivíduo com o trabalho.

[aposentadoria] essa parte é cruel, eu tinha 41 anos quando recebi o diagnóstico, e com 43 anos me aposentei. Não teve nenhuma preparação; na verdade, você sabe que aquilo vai acontecer, mais cedo ou mais tarde vai acontecer; para mim foi um baque bem grande [...] (P4)

[...] Nesse aspecto para mim foi um desastre, porque eu apostei todas as minhas fichas num doutorado, eu não tinha uma carreira consolidada, mas eu apostei que ao término do doutorado eu estaria prestando concurso para conseguir consolidar essa carreira. O que aconteceu? Recebi o diagnóstico, e caiu como uma bomba, porque em um semestre eu tive um declínio físico elevado, eu tinha carga horária muito grande. Então, no final do semestre, eles me mandaram embora [...] (P5)

\section{O inesperado da aposentadoria}

Muitas pessoas têm sua trajetória de trabalho interrompida por uma condição incapacitante, situação que pode ser observada neste relato. 
[...] a mais difícil foi a aposentadoria; [...] quando se está na terceira idade, já está aposentado, já cessou a idade ativa e aí vêm as doenças, não se está preparado para isso (P2)

Os participantes da pesquisa referiram que não houve um tempo para realizar tal preparação:

[...] não tive nenhuma preparação, a preparação foi minha. Então, assim, na época que eu estava afastada eu me preparei, eu não vou conseguir mais ter o mesmo ritmo", [...] e eu já não era mais a mesma, eu não poderia executar as mesmas tarefas, com a mesma rapidez, com a mesma energia, o ritmo era outro (P2)

[...] depois eu fui descobrir que, para essa parte da medicina do trabalho, eles não têm esse entendimento, porque eles estão contratando alguém que não sabe quanto tempo de vida produtiva ainda vai ter, então para mim isso foi um choque, virou minha vida de cabeça para baixo (P5)

\section{DISCUSSÃO}

Na sociedade capitalista, o ser humano é avaliado pelo que produz, e o sustento pessoal e familiar é provido pelo trabalho. Entre as atividades laborais, apenas as que são realizadas fora do contexto doméstico é que têm valor e reconhecimento nesse contexto cultural, influenciando fortemente a história pessoal dos indivíduos ${ }^{(10)}$.

Sob o olhar da psicologia, o trabalho é uma afirmação da autoestima e valorização do ser humano diante da sociedade que o cerca, e por este motivo, a aposentadoria pode afetar o bem-estar físico e psicológico ${ }^{(11)}$. O trabalho identifica a pessoa em relação às suas capacidades e ao sentido de pertencimento a um grupo e ao valor que isso representa para si e para os outros.

Quando comparados com a população em geral, indivíduos com DP tornam-se indisponíveis para a força de trabalho mais cedo do que aqueles sem a doença ${ }^{(12)}$, como observado nos depoimentos das categorias "aposentadoria e a identidade na doença de Parkinson"; "incompatibilidade entre o desejo e a capacidade para o trabalho". As flutuações off, o congelamento e as discinesias exibem associações estatisticamente significativas à indisponibilidade da força de trabalho como os principais fatores para a aposentadoria precoce no caso da DP, ocasionando maior dificuldade de aceitar esse momento, gerando repercussões principalmente na instabilidade emocional ${ }^{(12)}$.

Recente revisão sistemática de literatura sobre a capacidade de trabalho na DP constatou que nem sempre eram atendidos pedidos de ajuste de função de muitos empregados com DP. Resultados apresentados no estudo demonstram que trabalhadores com doença crônica antes da aposentadoria podem ter os sinais e sintomas acentuados após esse processo, justamente pela exacerbação dos fatores psicológicos e emocionais, principalmente em doença neurodegenerativa como a DP, que produz efeito prejudicial sobre a capacidade de trabalho e está associada a custos elevados e alta perda de ganhos individuais ao longo da vida ${ }^{(13)}$.

A capacidade de trabalho e a independência são duas atividades importantes da vida diária de particular preocupação para as pessoas com DP, que desejam desde a notícia do diagnóstico saber quanto tempo a sua capacidade pode perdurar ${ }^{(14)}$. Assim como relatado pelos participantes do presente estudo, as mudanças oriundas da doença interferem também nas capacidades do trabalhador para exercer suas 
atividades de acordo com o que esperam dele.

Outro estudo sobre aposentadoria revelou o impacto negativo das DCNTs numa população em idade produtiva com alta percentagem de aposentadorias precoces, além de gerar custos sociais para os indivíduos e famílias ${ }^{(15)}$. Esse fato é comprovado pelos relatos dos participantes de que se sentem desestruturados com a imposição de aposentar-se ainda em idade produtiva, destruindo sonhos profissionais e reduzindo a importância social do indivíduo.

Ao analisar os resultados desta pesquisa, verifica-se que cada vez mais cedo trabalhadores economicamente ativos se ausentam do mercado de trabalho por causa de alterações físicas e emocionais decorrentes de problemas de saúde. No caso da DP, os sinais e sintomas da patologia foram levantados pelos participantes como inviabilizadores de sua permanência em atividade no trabalho. Isso revela um grande problema, porquanto o afastamento das atividades laborais provoca repercussões tanto sociais como econômicas, onerando o aposentado com danos físicos e psicológicos. Sobre o governo recai o custo dos gastos em saúde pública e previdenciária, já que o trabalhador deixa de produzir e contribuir, tornando-se dependente de benefícios da previdência ${ }^{(16)}$.

Por suas características, a doença de Parkinson resulta em alterações motoras, e sendo crônica e degenerativa, o mais provável é que tais dificuldades evoluam com o passar do tempo ${ }^{(2)}$. Como relatado por um dos participantes do presente estudo, observa-se que a lentidão imposta pela doença é uma incapacidade não aceita num mundo de trabalho centrado na produtividade. A incompatibilidade entre o desejo de fazer e a capacidade de realizar leva a pessoa com DP a ser encaminhada à aposentadoria precocemente. Os depoimentos revelam ainda que as alterações físicas podem ser limitantes para o exercício das atividades profissionais, levando a atestados médicos sucessivos até culminar com a aposentadoria.

Corroborando resultados desta pesquisa, em estudo que objetivou investigar e comparar a percepção de saúde e qualidade de vida de trabalhadores ativos e afastados do trabalho, os autores identificaram que as pessoas afastadas tinham qualidade de vida pior nos domínios capacidade funcional, aspecto físico, dor, estado geral de saúde, aspecto social, aspecto emocional e saúde mental quando comparadas aos trabalhadores ativos. Revelam ainda pior percepção de saúde e qualidade de vida, que diminuem o leque de possibilidades de inserção no mundo do trabalho ${ }^{(17)}$. Esses resultados permitem a reflexão sobre o impacto do afastamento do trabalho e da importância de pesquisas voltadas para a aposentadoria devido às DCNTs.

Em algumas culturas como a nossa, o papel profissional é um dos pilares da autoestima, identidade e senso de utilidade, uma vez que o trabalho é um dos aspectos fundamentais da identidade individual, como o próprio nome, o sexo e a nacionalidade, ao ligar o presente ao futuro ${ }^{(7)}$. Nos relatos dos participantes constata-se que a aposentadoria por invalidez acarreta impacto emocional negativo nas pessoas com Parkinson. A ruptura repentina com o trabalho e a interrupção de projetos futuros causa sofrimento psíquico a essas pessoas, que precisam aprender a adaptar-se à novas condições físicas enquanto perdem funções sociais, como a vida laboral.

As falas demonstram que a pessoa que vivencia a aposentadoria por DP é desligada do mundo do 
trabalho e precisa enfrentar o convívio com o novo diagnóstico de saúde e compreender a expectativa de futuro com a doença.

Ao aproximar-se a época da aposentadoria, as pessoas vivenciam sentimentos ambíguos: de dever cumprido e liberdade, mas também de tristeza e incerteza quanto ao futuro. $O$ processo de preparação da aposentadoria deveria iniciar com a introdução da vida laborativa do indivíduo, por constituir-se um desafio para a área de gestão de pessoas, principalmente nas práticas que visam ao bem-estar dos trabalhadores ${ }^{(8)}$. Sendo assim, os Programas de Preparação para a Aposentadoria (PPA) são previstos pela Política Nacional do Idoso e o Estatuto do Idoso, como ações de promoção de saúde e qualidade de vida. Esse programa tem como principal objetivo preparar as pessoas para a aposentadoria, esclarecer dúvidas, auxiliar na descoberta de novas atividades, lidar com as finanças e cuidar da saúde ${ }^{(18)}$.

Resultados de pesquisa realizada com pessoas que se aposentaram por tempo de serviço sem ter uma preparação para a aposentadoria apontaram as mesmas dificuldades de adaptação citadas nos relatos dos participantes do presente estudo. A pesquisa revelou também o sofrimento vivenciado no momento da ruptura com o meio produtivo ${ }^{(19)}$.

Diante da aposentadoria inesperada, os profissionais de saúde podem auxiliar nesta preparação, podendo aumentar o potencial de saúde e bem-estar do indivíduo após desligar-se do trabalho. Entre as ações para tal, destaca-se o apoio a essas pessoas, ajudando-as a buscar transformações pessoais para enfrentar essa etapa ${ }^{(20)}$. O profissional deve contribuir para maximizar as potencialidades das pessoas com DP, estimulando-as a descobrir novas habilidades para um viver saudável, mesmo diante de condição crônica de saúde.

\section{CONCLUSÃO}

Dentre as DCNTs, a DP merece destaque devido às suas características. O presente estudo permitiu compreender a relação do trabalho com a doença de Parkinson, revelando dimensões do enfrentamento da vivência com a doença e, nesse caso, o processo de ruptura com o trabalho até a aposentadoria por invalidez.

Além das alterações físicas, a DP gera complicações psicológicas que podem ser intensificadas com o processo de aposentadoria precoce, principalmente quando faltam acompanhamento adequado e preparação prévia para vivenciar tal momento.

Diante dos achados, constata-se que a aposentadoria precoce é um aspecto que deve ser aprofundado em futuros estudos, em especial envolvendo a enfermagem e a DP. Nesse sentido, o estudo traz contribuições para a enfermagem (re)pensar a prática profissional dirigida à pessoa com doença de Parkinson, principalmente em idade ativa. Constatou-se a insatisfação das pessoas com a aposentadoria precoce e a necessidade de ações que ressignifiquem o processo de aposentadoria, desenvolvendo medidas que permitam a permanência da pessoa com DP no mercado de trabalho. Essas medidas podem envolver reabilitação vocacional, redução da carga horária de trabalho ou intervenções com o intuito de proporcionar uma transição entre as mudanças de papéis na busca de um viver produtivo, de forma a minimizar o 
sofrimento das pessoas com DP.

Considerando-se a escassez de literatura científica nacional sobre a temática aposentadoria por invalidez e a DP, reafirma-se a importância de pesquisas nessa área, principalmente por profissionais de saúde, pela necessidade de um olhar para a integralidade do sujeito, cuja desinserção do trabalho interfere de maneira decisiva sobre sua condição de saúde.

\section{REFERÊNCIAS}

1. Kalia, LV, et al. Parkinson disease. The Lancet. 2015; 386 (9996): 896-912.

2. Pinheiro JES. Doença de Parkinson e outros transtornos do movimento. In: Freitas EV, Py L. Tratado de Geriatria e Gerontologia. 4. ed. Rio de Janeiro: Guanabara Koogan; 2016, p. 285-291.

3. Dias BL, Santos TB, Dias ADP, Correia NI, Ximenes PCMA, Oliveira VM. Revista Inspirar Movimento \& Saude. 2015, 7

(4):9-12.

4. Gustafsson H, Nordström P, Stråhle S, Nordström A. Parkinson's Disease: A population based investigation of life satisfaction and employment. J Rehabil Med. 2015; 47:45-5.

5. Murphy R, Tubridy N, Kevelighan H, O'Riordan S. Parkinson's disease: how is employment affected? Ir J Med Sci. 2013; 182: 415- 9 .

6. Bovolenta TM; Felicio AC. O doente de Parkinson no contexto das Políticas Públicas de Saúde no Brasil. Einstein (São Paulo), 2016; 14(3):7-9.

7. Brasil. Anuário Estatístico da Previdência Social/Ministério da Previdência Social, Empresa de Tecnologia e Informações da Previdência Social. Brasília, 2015; [acesso em: 17 fev 2017]. Disponível em:

http://www.previdencia.gov.br/wp-content/uploads/2015/08/AEPS-2015-FINAL.pdf.

8. Antunes $\mathrm{MH}$, Moré CLOO. Aposentadoria, saúde do idoso e saúde do trabalhador: revisão integrativa da produção brasileira. Revista Psicologia Organizações e Trabalho. 2016. 16(3):248-258.

9. Strauss A, Corbin J. Pesquisa qualitativa: técnicas e procedimentos para o desenvolvimento de teoria fundamentada. 2. ed. Poro Alegre: Artmed; 2008.

10. Bressan MALC, Mafra SCT, França LHFP, Melo MSS, Loreto MDS. Trabalho versus aposentadoria: desvelando sentidos e significados. Rev Bras de economia doméstica. 2012. 23(1):226-50.

11. Van der Heide I, Van Rijn RM, Robroek SJ, Burdorf A, Proper KI. Is retirement good for your health?. BMC Public Health. 2013; 13:1180.

12. Timpka J, Svensson J, Nilsson MH, Pålhagen S, Hagell P, Odin. Workforce unavailability in Parkinson's disease. Acta Neurologica Scandinavica. 2016.

13. Koerts J, König M, Tucha L, Tucha O. Working capacity of patients with Parkinson's disease-A systematic review. Parkinsonism \& related disorders, 2016; 27: 9-24.

14. Jasinska-Myga B, Heckman MG, C Wider, Putzke JD, Wszolek ZK, Uitti RJ. Loss of ability to work and ability to live independently in Parkinson's Disease. Parkinsonism Relat Disord. 2012; 18 (2):130-135.

15. Santos ACQ, Limongi JE, Jorge MLMP, Jorge MT, Pereira BB, Jorge PT. Aposentadorias por invalidez e Doenças Crônicas entre os servidores da Prefeitura Municipal de Uberlândia, Minas Gerais, 1990-2009. Cadernos Saúde Coletiva. 2015; 23(1):57-62.

16. Santos TR, Silva Júnior WR, França ISX, Cavalcanti AL, Fernandes MGM. Perfil socioeconômico-demográfico do beneficiário do Instituto Nacional do Seguro Social aposentado por invalidez e suas causas, no Estado da Paraíba, no quinquênio 2007-2011. R. bras. Est. Pop. 2012; 29(2):349-359.

17. Dutra F, Costa L, Sampaio R. A influência do afastamento do trabalho na percepção de saúde e qualidade de vida de indivíduos adultos. Fisioterapia e Pesquisa, 2016; 23(1):98-104.

18. França CL, Murta SG, Negreiros JL, Pedralho M, Carvalhedo R. Intervenção Breve na Preparação para Aposentadoria. Revista Brasileira de Orientação Profissional, 2013;14(1):99-110.

19. Novo LF, Fôlha FAS. Importância de preparação à aposentadoria: a fala de servidores aposentados da UFPEL. X Colóquio Internacional sobre Gestion Universitaria em America del Sur. 2010. 
20. Gvozd, R., Garcia SD, Haddad MDCL, Vannuchi MTO, Garanhani ML. Teoria tornar-se humano: prática em grupo de pré-aposentadoria. Revista de Enfermagem da UFSM. 2016; 6(1):40-49. 